\title{
Prospective estimation of duration of pregnancy in women attending antenatal care at the Sultania Zanana Hospital, Gandhi Medical College Bhopal, Madhya Pradesh, India
}

\section{Megha Goyal*, Rekha Wadhwani}

\begin{abstract}
Department of Obstetrics and Gynaecology, Sultania Zanana Hospital, Gandhi Medical College Bhopal, Madhya Pradesh, India
\end{abstract}

Received: 25 May 2016

Accepted: 13 June 2016

\author{
*Correspondence: \\ Dr. Megha Goyal, \\ E-mail: goyaldrmegha@gmail.com
}

Copyright: (C) the author(s), publisher and licensee Medip Academy. This is an open-access article distributed under the terms of the Creative Commons Attribution Non-Commercial License, which permits unrestricted non-commercial use, distribution, and reproduction in any medium, provided the original work is properly cited.

\begin{abstract}
Background: Correct assessment of pregnancy duration and fetal growth is essential for optimal obstetric management. The objective of this study was to estimate the accuracy of Naegele's formula in estimation of gestational age and duration of pregnancy in Sultania Zanana Hospital, Bhopal, Madhya Pradesh, India. Hospital based prospective observational study. Department of obstetrics and gynecology, Sultania Zanana Hospital, Gandhi Medical College, Bhopal, a one year study from April 2014 to March 2015.

Methods: This was a prospective observational study of 500 antenatal women selected at random with regular menstrual cycle, which knew their last menstrual period and delivered spontaneously in Sultania Zanana hospital between April 2014 to March 2015. The mean duration of pregnancy was calculated using Naegele`s formula.

Results: Most of the patients were in their $2^{\text {nd }}$ decade of life. Most of them were para 2, 3 and 4 . The mean duration of pregnancy was $276.04 \pm 8$ days.

Conclusions: The duration of pregnancy 276 days appears more applicable in our environment.
\end{abstract}

Keywords: LMP, EDD, Gestational age, Naegele`s rule

\section{INTRODUCTION}

Correct assessment of pregnancy duration and fetal growth is essential for optimal obstetric management. ${ }^{1}$ Accurate estimation of gestational age early in pregnancy is paramount for obstetric care decisions and for determining fetal growth and other condition that may necessitate timing the iatrogenic intervention or delivery. ${ }^{2}$ The expected date of delivery is traditionally calculated by using Naegele's rule by counting back three calendar months from the first day of the last menstrual period and adding one week. This rule presumes that the menstrual cycles of the female are regular and of 28 days. ${ }^{3}$ Currently obstetrician simply use a gestation calculator to calculate the expected due date by adding 280 days to the last menstrual period irrespective of the actual length in individual patient. This study aims to access the accuracy of Naegele's formula in our hospital section. This will help to recommend if EDD needs to be corrected depending upon the length of individual patient menstrual cycle. This will help improve our precision in determining the expected due date in our patients.

\section{METHODS}

Between April 2014 to March 2015, 500 cases were included in the study at Sultania Zanana Hospital, Bhopal, Madhya Pradesh, India. This was an 
observational prospective study. The women were randomly selected from antenatal women attending Sultania Zanana Hospital. Verbal informed consent was obtained from the study participants.

\section{Inclusion criteria}

All the eligible participants who have

- Regular cycles

- Must know her last menstrual period

- Have full term pregnancy

\section{Exclusion criteria}

- Multiple pregnancies

- Preterm birth

- Elective cesarean section not preceded by established labour

- Induced pregnancy

- Women not sure of her LMP

- Women with irregular cycles

The expected date of delivery was calculated using Naegele`s formula (9 months from LMP+7 days) for each subject.

The mean duration of pregnancy and standard deviation was calculated using the formula.

$$
\text { Mean }=\frac{\text { Sum of all data values }}{\text { Number of data values }}
$$

Symbolically,

Where,

$$
\bar{x}=\frac{\sum x}{\mathrm{n}}
$$

$\bar{x}=($ read as ' $x$ bar') is the mean of the set of $\mathrm{x}$ values, $\sum x$ is the sum of all the $\mathrm{x}$ values, and $\mathrm{n}$ is the number of $\mathrm{x}$ values.

$$
\sigma=\sqrt{\frac{\sum(x-\bar{x}) 2}{n}}
$$

Where,

$\sigma=$ standard deviation

$\Sigma=$ sum of

$\mathrm{x}=$ each value in the data set

$\bar{x}=$ mean of all values in data set

$\mathrm{N}=$ number of value in a data set

\section{RESULTS}

Out of total 500 women, $410(82 \%)$ were in the $2^{\text {nd }}$ decade of life. This may be because our hospital caters the area where early marriages are common (Table 1).
Table 1: Age distribution of subjects.

\begin{tabular}{|ll|}
\hline Age range & Number of subjects \\
\hline$<20$ years & 50 \\
\hline $21-30$ years & 410 \\
\hline $31-40$ years & 40 \\
\hline
\end{tabular}

Most of the subjects ( $82 \%$ ) were in the 2 nd decade of their life.

Out of total 500 women, $280(56 \%)$ were para 2, para 3 or para 4 (Table 2).

Table 2: Parity distribution of subjects.

\begin{tabular}{|ll|}
\hline Parity & Number of subjects \\
\hline P1 & 200 \\
\hline P2-p4 & 280 \\
\hline$>$ p4 & 20 \\
\hline
\end{tabular}

Most of the subjects $(56 \%)$ were para 2, para 3 or para 4 ; followed by para $1(40 \%)$.

Table 3: Duration of pregnancy.

\begin{tabular}{|l|l|}
\hline Duration of pregnancy (days) & Frequency $(\mathbf{x} \mathbf{1})$ \\
\hline 262 & 25 \\
\hline 263 & 20 \\
\hline 265 & 15 \\
\hline 268 & 12 \\
\hline 269 & 15 \\
\hline 270 & 25 \\
\hline 271 & 40 \\
\hline 272 & 18 \\
\hline 273 & 25 \\
\hline 274 & 32 \\
\hline 275 & 32 \\
\hline 276 & 32 \\
\hline 277 & 25 \\
\hline 278 & 25 \\
\hline 279 & 52 \\
\hline 280 & 32 \\
\hline 281 & 25 \\
\hline 282 & 20 \\
\hline 283 & 10 \\
\hline 284 & 5 \\
\hline 286 & 5 \\
\hline 290 & 5 \\
\hline 291 & 5 \\
\hline
\end{tabular}

The mean duration of pregnancy was 276.04 days with standard deviation 8 days.

The mean duration of pregnancy as calculated by Naegele`s formula is $276.04 \pm 8$ days (Table 3). 


\section{DISCUSSION}

In our study the mean duration of pregnancy in our population is 276.04 days with standard deviation of 8 days.

The mean duration of pregnancy 281 days with a standard deviation of 13 days was the result of a population based study of 427,581 singleton births in Sweden. ${ }^{4}$

The mean duration of pregnancy 281 days for $1^{\text {st }}$ time mothers and 280 days for all others were the medians found by a 1995 American study of 1970 spontaneous births. Standard deviation was 7-9 days. ${ }^{5}$

Several other researchers have suggested modifications in the presumed gestational age of 280 days.

Mittendorf $\mathrm{R}$ et al in their study found the median duration of gestational age of 288 days for primipara and 283 days for multipara. ${ }^{6}$

The reasons for these variations are still poorly understood, but it is likely due to physiological reasons. The physiological variation in the natural duration of pregnancy makes it impossible to predict the day of delivery beyond a certain limit. Moreover, Naegele' rule presumes that the menstrual cycle is regular and of 28 days. If a woman gives history of regular, longer or shorter cycles, her EDD needs to be corrected. Unawareness about this correction and strict adherence to Naegele's rule lead to erroneous EDD in women with cycles shorter or lengthier than 28 days.

\section{CONCLUSION}

The duration of $276 \pm 8$ days instead of 280 days (as based on Naegele's formula) appears more applicable in our environment. This may be due to physiological variation and variation in cycle length. Correction of Naegele's formula may lead to more accurate estimation of gestational age.

\section{ACKNOWLEDGEMENTS}

After thanking the almighty, Authors take this opportunity to express my deepest feelings of respect and gratitude to all those helping hands that made this endeavour of mine successful. I express heartily thanks to all the patients and nursing staff subjected to this study without whose co-operation and participation this would ever have been possible.

\section{Funding: No funding sources \\ Conflict of interest: None declared \\ Ethical approval: Not required}

\section{REFERENCES}

1. Verburg BO, Steegers EAP, DeRidder M, Snijders RJM, Smith E, Hofman, et al. New charts for ultrasound dating in pregnancy and assessment of fetal growth: longitudinal data from a population based cohort study. Ultrasound Obstet Gynecol. 2008;31(4):388-96.

2. Ananth CV. Menstrual versus clinical estimate of gestational age dating in the United States: temporal trends and variability in indices of perinatal outcomes. Paediatr Perinat Epidemiol. 2007:21(2):22-30.

3. Parikh R, Pandia K. Erroneous calculation of the expected date of delivery by medical professionals. Chron Young Sci. 2011;2:171-3.

4. Bergso P, Denmam DW, Hoffman HJ, Meirik O. Duration of human singleton pregnancy. A population-based study. Acta Obstet Gynaecol Scand. 1990;69:197-207.

5. Kieler H, Axelsson O, Nilsson S, Waldenstrom U. The length of human pregnancy as calculated by ultrasonographic measurement of the fetal biparietal diameter. Ultrasound Obstet Gynecol. 1995;6:35377.

6. Mittendorf R, Williams MA, Berkey CS, Cotter PF. The length of uncomplicated human gestation. Obstet Gynecol. 1990;75:929-32.

Cite this article as: Goyal M, Wadhwani R. Prospective estimation of duration of pregnancy in women attending antenatal care at the Sultania Zanana Hospital, Gandhi Medical College Bhopal, Madhya Pradesh, India. Int J Reprod Contracept Obstet Gynecol 2016;5:2392-4. 